\title{
Seramik Sağıık Gereci Atığı Esaslı Geopolimer Harçların Ortam Küründe Üretim Özelliklerinin İncelenmesi
}

\author{
Zahide BAYER ÖZTÜRK ${ }^{1 a}$, Serhat ÇELİKTEN ${ }^{2 b}$, İsmail İsa ATABEY ${ }^{2 c}$ \\ ${ }^{1}$ Nevşehir Hacı Bektaş Veli Üniversitesi, Mühendislik-Mimarlık Fakültesi, Metalurji ve \\ Malzeme Mühendisliği, Nevşehir, Türkiye \\ ${ }^{2}$ Nevşehir Hacı Bektaş Veli Üniversitesi, Mühendislik-Mimarlık Fakültesi, İnşaat \\ Mühendisliği, Nevşehir, Türkiye \\ z.ozturk@nevsehir.edu.tr
}

Received/Geliş: 06.04.2021

Accepted/Kabul: 02.05.2021

\begin{abstract}
Öz: Bu çalışmada, seramik sağlık gereç iüretimi esnasında ortaya çıkan hatalı ürünlerin öğütülmesi ile elde edilen atık tozların metakaolen ile \%10,20, 30, 40, 50 oranlarında ağırlıkça yer değişimi ile sodyum silikat ile aktive edilerek geopolimer harçlar üretilmiştir. Üretilen harçlarda seramik sağlık gereci atıkları (SGA) yerine metakaolen (MK) ilavesinin ve ortam küründe kür süresinin fiziksel ve mekanik özelliklere etkisi incelenmiştir. $\mathrm{Bu}$ amaçla harçlarda sıvı/bağlayıcı oranı $0,50, \mathrm{kum} /$ bağlayıcı oranı 3 ve sodyum silikat ise $\% 10 \mathrm{Na}_{2} \mathrm{O}$ oranında kullanılmıştır. Üretilen harç karışımları, $23 \pm 2{ }^{\circ} \mathrm{C}$ 'de laboratuvar ortamında kalıpta sertleşinceye kadar bekletilmiştir. Numunelere yayılma çapı, birim ağırlık, su emme ve boşluk oranı, eğilme ve basınç dayanımı deneyleri uygulanmıştır. SGA yerine MK ilavesi su emme, boşluk oranı ve basınç dayanımı özelliklerine olumlu etkisi olmamakta ancak yayılma çapı ve eğilme dayanımını iyileştirmiştir. Seramik sağlık gereci atıklarının yüksek olduğu numunelerde ise su emme ve boşluk oranı düşük, basınç dayanımları yüksek çıkmıştır. Ayrıca, kür süresi arttıkça harçların eğilme ve basınç dayanımları farklı oranlarda artmıştır. En yüksek basınç dayanımı 21,4 MPa ile \%100 SGA ile elde edilirken en yüksek Eğilme dayanımı $8 \mathrm{MPa}$ ile \%20 MK içeren 56 günlük numunelerde elde edilmiştir. Basınç dayanımı, su emme, boşluk oranı, çevresel ve ekonomik koşullar açısından seramik sağlık gereci atıkları esaslı geopolimerlerin havada kür koşullarında geopolimer özelliklerinin gelişebileceği tespit edilmiştir.
\end{abstract}

Anahtar Kelimeler: Seramik Sağlık Gereci; Geopolimer; Harç; Mekanik özellikler.

\section{The Investigation of Production Properties of Geopolymer Mortars Incorporated Ceramic Sanitaryware Wastes Subjected to Ambient Curing Conditions}

\begin{abstract}
In this study, geopolymer mortars were produced by activating with sodium silicate the waste powders obtained by grinding the defective products during the production of ceramic sanitaryware with 10 , $20,30,40,50 \%$ by weight displacement with metakaolin. The effects of the addition of metakaolin (MK) instead of ceramic sanitaryware wastes (SGA) and curing time of ambient curing were investigated on the physical and mechanical properties of produced mortars. For this purpose, the liquid / binder ratio is 0.50 , sand / binder ratio is 3 and sodium silicate is used at $10 \% \mathrm{Na}_{2} \mathrm{O}$ ratio in mortars. The produced mortar mixtures were kept in the laboratory at $23 \pm 2{ }^{\circ} \mathrm{C}$ until hardened in the mold. Flow table, unit weight, water absorption and void ratio, flexural and compressive strength tests were applied to the samples. Adding MK instead of SGA does not have a positive effect on water absorption, void ratio and compressive strength properties, but it has improved workability and flexural strength. The water absorption and void ratio of the samples containing high ceramic sanitaryware wastes was low and the compressive strength was higher than other samples. In addition, as the curing time increased, the flexural and compressive strength of the mortars increased at different rates.
\end{abstract}


While the highest compressive strength was obtained as $21.4 \mathrm{MPa}$ for sample with $100 \%$ SGA, the highest flexural strength was obtained as $8 \mathrm{MPa}$ for sample containing 20\% MK in 56-day. In terms of compressive strength, water absorption, void ratio, environmental and economic conditions, it has been determined that geopolymers based on ceramic sanitaryware wastes can improve their geopolymer properties under air curing conditions.

Keywords: Sanitaryware, Geopolymer, Mortar, Mechanicalproperties

\section{Giriş}

Geopolimerler, üstün mekanik özellikleri, dayanımı, Portland çimento üretimine kıyasla daha az sera gazı salınımı sayesinde çevresel koruma ve enerji tasarrufu özellikleri ile sürdürülebilir ilerleme perspektifinde gelecek vaat eden inorganik polimer malzemeler olarak karşımıza çımaktadır [1,2]. Geopolimer terimi genellikle, metakaolen, uçucu kül, yüksek firın cürufu gibi bir alümina silikatın oda sıcaklığında veya ısıl kürde alkali çözeltide karışım hazırlanması ile oluşan "çimentosuz malzeme", "alkali aktive karışımı" tanımlamak için kullanılır [2-6].

Son yıllarda, ham ve kalsine edilmiş killer, özellikle metakaolen ve çeşitli seramik üretim atıkları geopolimerlerin önemli bir parçası haline gelmiştir [7]. Ayrıca, bazı araştırmacılar tarafindan metakaolen bazlı geopolimerlerin termal [7-10], kimyasal [11,12] ve mekanik [10,13] özellikleri araştırılmıştır. Ancak, yüksek spesifik yüzey alanına bağlı olarak yüksek miktarda su ve alkali gereksinimi, bu gereksinime bağlı yüksek büzülme ve kırılganlı̆̆ı metakaolen bazlı geopolimer kullanımını sınırlı tutmaktadır [7]. Metakaolen, kaolenin kalsine edilmesiyle üretilen beyaz renkli, amorf yapılı bir alümina silikattır. Kaolen, $500-800{ }^{\circ} \mathrm{C}$ sıcaklık aralığında suyunu kaybederek metakaolinite dönüşür [14]. Metakaolen, kalsinasyon ürünü olması nedeniyle pahalı bir seçim olabilir[16]. Büyüyen inşaat sektörünün ihtiyaçlarına karşıllk verebilmek için alternatif atık malzemelerin kullanımı/değerlendirilmesi önem kazanmaktadır [17]. Günümüzde geopolimer üretiminde ana malzeme olarak atık seramik tozlarının kullanımı da alümina-silikat kaynağı olması ve seramik sektörünün endüstriyel atık sorununa yardımcı olması nedeniyle alkali aktivasyon sürecinde bilimsel çalışmaları, uygun endüstriyel atıkları belirlemeye yönlendirmiştir [19]. Literatürde yapılan çalışmalarda kırmızı çamur $[18,19]$, atık cam tozu[20], seramik karo atıkları[16, 21-23], kırmızı kil tozları[24], seramik sağlık gereci atıkları [25-27] kullanımlarının geopolimer ürün performansına etkileri incelenmiştir.

Seramik sağllk gereci, banyolarda ve mutfaklarda kullanılan lavabo, klozet, rezervuar, bide, duş teknesi ve pisuar gibi ürünleri kapsamaktadır. Bu ürünler, kir tutmayan, kolay temizlenebilir yüzeye ve estetik görünüme sahip, su, mekanik ve kimyasal etkilere karşı dayanıklı olup seramik sektörünün önemli malzemelerindendir[28]. Genel olarak kil, kaolen, feldispat ve kuvars ile hazırlanan hammadde karışımlarının alçı kalıplarda şekillendirilmesi, kurutulması, sırlanması ve yüksek sıcaklıkta pişirilmesi ile üretilen ürünleri kapsamaktadır [29, 30]. Yıllık üretimi 320000 tonu bulan bu ürünlerin üretimi esnasinda ve kalite kontrolü sonrasında oluşan atık miktarı ülkemizde büyük bir önem arz etmektedir [30]. Üretici firmalar, oluşan atı̆̆ın ancak \%5-7'sini geri değerlendirebilmektedir [31]. Bu durum bu atıkların farklı alanlarda kullanılabilir olmasını zorunlu kılmaktadır.

Genellikle 1sıyla sertleşebilen geopolimer harçlar üzerine çalş̧malar literatürde mevcuttur [32-34]. Ancak, literatür incelendiğinde, seramik sağlık gereci atıklarının alkali aktive harçlarda oda sıcaklığında kür koşullarını ele alan çalışmalar çok sınırlıdır. Metakaolen ve seramik sağlık gereci atıklarının beraber kullanımını ele alan çalışmalar ise araşıımalarımıza göre bulunmamaktadır. Ayrıca, son yıllarda yapılan çalışmalarda seramik atıklarının kullanımı ile oluşturulan geopolimerlerin gelişme gösteren özellikleri yapı malzemeleri sektörü için umut vaat edicidir. $\mathrm{Bu}$ nedenle, deneysel çalışmada seramik sağlı gereci üretiminde pişme sonrası 1skartaya ayrılan ürünlerin öğütülmesi ile elde edilen yüksek silis ve alümina içeriğine sahip atık tozlar ve alümina 
içeriği zengin metakaolenin birlikte kullanımı ile üretilen geopolimer harçların fiziksel ve mekanik özelliklerinin değişimi incelenmiştir.

\section{Deneysel Çalışmalar}

\subsection{Kullanılan Malzeme Özellikleri}

Harç üretimi için seramik sağlık gereci pişmiş ürün toz atıkları (SGA), metakaolen (MK), dere kumu, $\mathrm{Na}_{2} \mathrm{SiO}_{3}$ ve su kullanılmıştır. Dere kumunun doygun kuru yüzey (DKY) özgül ağırlı̆̆ 2,66 iken su emme oranı \%1,97'dir [35]. Kumun elek analizi sonuçları Tablo 1'de verilmiştir. Aktivatör olarak kullanılan sodyum silikat $\left(\mathrm{Na}_{2} \mathrm{SiO}_{3}\right)$ çözeltisinde \%61 $\mathrm{H}_{2} \mathrm{O}, \% 26 \mathrm{SiO}_{2}, \% 13 \quad \mathrm{Na}_{2} \mathrm{O}$ bulunmaktadır. Karışımlarda şehir şebekesi içme suyu kullanılmıştır [36]. Harç karışımlarında SGA malzemesine farklı oranlarda ikame edilen MK malzemesinin yoğunluğu $2,42 \mathrm{~g} / \mathrm{cm}^{3}$ 'dür. Atık seramik sağlık gereci, Turkuaz Seramik (Kayseri) firmasından öğütülmüş toz olarak temin edilmiştir. SGA ve MK malzemelerine ait kimyasal analiz sonuçları Tablo 2'de verilmiştir.

Tablo 1. Dere kumunun elek analizi

\begin{tabular}{cc}
\hline Elek Çapı, $\mathbf{m m}$ & Geçen, $\%$ \\
\hline 4,00 & 99,1 \\
2,00 & 65,1 \\
1,00 & 40,2 \\
0,50 & 21,3 \\
0,25 & 9,9 \\
0,125 & 3,7 \\
0,063 & 0,9 \\
\hline
\end{tabular}

Tablo 2. Seramik sağlık gereci atığg ve metakaolenin kimyasal analizi, \%

\begin{tabular}{ccccccccccc}
\hline & $\mathbf{S i O}_{2}$ & $\mathrm{Al}_{\mathbf{2}} \mathbf{O}_{3}$ & $\mathbf{K}_{2} \mathbf{O}$ & $\mathrm{Na}_{2} \mathbf{O}$ & $\mathbf{C a O}$ & $\mathbf{M g O}$ & $\mathbf{F e}_{2} \mathbf{O}_{3}$ & $\mathbf{T i O}_{2}$ & $\mathbf{P}_{\mathbf{2}} \mathbf{O}_{5}$ & $\begin{array}{c}\text { Kizdırma } \\
\text { Kaybı }\end{array}$ \\
\hline SGA & 66,32 & 27,86 & 1,56 & 0,37 & 1,07 & 0,16 & 1,25 & 0,59 & 0,05 & 0,10 \\
MK & 50,93 & 43,47 & 0,63 & 0,12 & 0,11 & 0,18 & 1,44 & 1,68 & 0,09 & 1,10 \\
\hline
\end{tabular}

\subsection{Yöntem}

$\mathrm{Bu}$ deneysel çalışmada, MK içeriğine bağlı olarak 5 farklı harç karışımı hazırlanmıştır. $\mathrm{Kum} /$ bağlayıcı oran 3 olarak seçilmiştir. Karışıma giren malzeme miktarları Tablo 3 'de verilmiştir. MK0 karışımı için 450 g SGA malzemesi kullanılmış olup diğer karışımlar için \%10-20-30-40 ve 50 oranlarında atık miktarı azaltılarak MK ikamesi yapılmıştır. Hazırlanan harçlarda sıvı/bağlayıcı oranı 0,50 seçilmiştir. Aktivatör olarak sıvı sodyum silikat karışımlardaki SGA ve MK ağırlıkları toplamının \%10'u kadar $\mathrm{Na}_{2} \mathrm{O}$ içerecek miktarda kullanılmıştır. Sıvı sodyum silikatın $\left(\mathrm{Na}_{2} \mathrm{SiO}_{3}\right)$ kimyasal bileşimi \%61 $\mathrm{H}_{2} \mathrm{O}, \% 26 \mathrm{SiO}_{2}, \% 13 \mathrm{Na}_{2} \mathrm{O}$ 'dan oluşmaktadır. Toz bağlayıcının ağırlığının \%10'u kadar $\mathrm{Na}_{2} \mathrm{O}$ için $228 \mathrm{~g}$ sıvı sodyum silikata ihtiyaç duyulmaktadır. Kullanılan sıvı sodyum silikatın kimyasal içeriğine göre yaklaşık \%61'i su olduğu için bu oranda su 225 g'dan (s/b:0,50 için) azaltılarak ilave $86 \mathrm{~g}$ su eklenmiştir. Çözelti hazırlamak için cam kavanozlara ilave su miktarı, sıvı sodyum silikatın üzerine ilave edilmiştir. Çözeltiler ile standarda uygun olarak 40×40×160 mm üç gözlü kalıplarda numuneler üretilmiştir [37]. Çözelti ve SGA ve MK malzeme karışımı önce karıştırma kabına konup 30 saniye karıştırdıktan sonra ikinci 30 saniye içerisinde kum ilave edilmiştir. Daha sonra yüksek hızda 30 saniye daha karıştırmaya devam edilmiştir. Karıştırıcı 
durdurulup ilk 30 saniyede kabın çeperlerindeki harç ortaya toplanarak toplam 90 saniye beklenmiştir. Ardından 60 saniye daha yükssek hızda devam edilerek karıştırma işlemi tamamlanmıştır. Taze halde iken harçlar üzerinde TS EN 1015-3 [37] standardına uygun olarak yayılma tablası deneyi gerçekleştirilmiştir. Ardından karışımlar $40 \times 40 \times 160 \mathrm{~mm}$ boyutlarında 3 göze sahip harç kalıplarına iki aşamada yerleștirilmiștir. 3 gözlü harç kalıplarına dökülen karıșımlar kalıplarıyla birlikte havada 48 saat, kalıptan çıkarıldıktan sonra laboratuvar koşullarında yaklaşık $23 \pm 2{ }^{\circ} \mathrm{C}$ sıcaklıkta 28,56 ve 90 gün bekletilmiştir. 28 günlük numunelerin birim ağırlıkları ile su emme ve boşluk oranları belirlenmiştir. Sertleşmiş harç numuneleri üzerinde TS EN 1015-11 standardına uygun olarak eğilme ve basınç dayanımı deneyleri uygulanmıştır [38]. Her bir deneysel değer 3 numuneden elde edilen sonuçların ortalaması alınmak suretiyle belirlenmişstir.

Tablo 3. Harç karışım oranları

\begin{tabular}{cccccc}
\hline $\begin{array}{c}\text { Numune } \\
\text { Kodu }\end{array}$ & $\begin{array}{c}\text { Metakaolen } \\
\text { (MK), } \mathbf{g}\end{array}$ & $\begin{array}{c}\text { Seramik Sağlık } \\
\text { GereciAtığı (SGA), } \mathbf{g}\end{array}$ & Kum, g & $\mathbf{S u , g}$ & $\begin{array}{c}\text { Sivı } \\
\mathbf{N a}_{2} \mathbf{S i O}_{\mathbf{3}}, \mathbf{g}\end{array}$ \\
\hline MK0 & 0 & 450 & 1350 & 86 & 228 \\
MK10 & 45 & 405 & 1350 & 86 & 228 \\
MK20 & 90 & 360 & 1350 & 86 & 228 \\
MK30 & 135 & 315 & 1350 & 86 & 228 \\
MK40 & 180 & 270 & 1350 & 86 & 228 \\
MK50 & 225 & 225 & 1350 & 86 & 228 \\
\hline
\end{tabular}

\section{Sonuçlar ve Değerlendirme}

Deneysel çalışmada harç numunelerine taze halde iken yayılma tablası, 28 günlük numunelere ise birim ağırlık, su emme ve boşluk oranı deneyleri yapılmıştır. Ayrıca, numunelere 28, 56 ve 90 günlük eğilme dayanımı ve basınç dayanımı deneyleri uygulanmıştır. Numunelere ait sonuçlar Tablo 4 ve Şekil 1-2'de verilmiştir. Fiziksel özelliklerde, numunelerde MK'nin ağırlıkça \%0'dan \%40' a varan ölçüde SGA'nin yerine ilave edilmesi yayılma çap1 ve birim ağırlı değerlerini arttırmıştır. Numunelerin 28 günlük birim hacim ağırlıkları 2,01-2,11 g/ $\mathrm{cm}^{3}$ ve su emme oranları $\% 10,1-10,6$ arasındadır. MK miktarı arttıkça, 28 gün sonunda \%boşluk oranı ve buna bağlı \%su emme oranının arttığı gözlemlenmiştir. Karışımdaki SGA'nin ince tane boyutunun harç numunelerinin daha yoğun mikroyapı gelişimine katkı sağladığı düşünülmektedir. Kür süresi arttıkça (28 günlük) numunelerde boşlukların dolu olması nedeniyle devam eden geopolimerik reaksiyonların etkisiyle su emme değerleri düşük, basınç dayanımları yüksektir.

Tablo 4. Numunelere ait fiziksel özellikler

\begin{tabular}{ccccc}
\hline $\begin{array}{c}\text { Numune } \\
\text { Kodu }\end{array}$ & $\begin{array}{c}\text { Yayılma Çapı, } \\
\text { mm }\end{array}$ & $\begin{array}{c}\text { Birim Ağırlık, g/cm } \\
\text { (28 Günlük) }\end{array}$ & $\begin{array}{c}\text { Su Emme Oranı, \% } \\
\text { (28 Günlük) }\end{array}$ & $\begin{array}{c}\text { Bossluk Oranı, \% } \\
\text { (28 Günlük) }\end{array}$ \\
\hline MK0 & 119 & 2,01 & 10,1 & 19,2 \\
MK10 & 135 & 2,07 & 10,0 & 19,3 \\
MK20 & 146 & 2,01 & 10,3 & 20,0 \\
MK30 & 148 & 2,06 & 10,0 & 20,2 \\
MK40 & 137 & 2,09 & 10,4 & 20,5 \\
MK50 & 135 & 2,11 & 10,6 & 20,9 \\
\hline
\end{tabular}

Üretilen harçların eğilme dayanımı ve basınç dayanımlarındaki değişimler Şekil 1 ve 2'de sunulmuştur. Geopolimer harçlarda laboratuvar koşullarındaki kür ortamında 5,6-7,4 MPa arasında 28 günlük eğilme dayanımı değerleri elde edilebilmiştir. Harçların 56 günlük eğilme dayanımları 28 günlük dayanımlarına göre \%1,3 ile \%7,7 arasında artarken, 90 günlük eğilme dayanımları da 56 
günlük dayanımlarına göre \%6,6 ile \%25 arasında değişen oranlarda artmıştır. Ayrıca, karışımlarda SGA yerine \%40'a kadar MK ilavesinin eğilme dayanımlarını arttırdığı tespit edilmiştir. En yüksek 28, 56 ve 90 günlük eğilme dayanımları MK20 kodlu harçlarda elde edilmiştir.

$\mathrm{Bu}$ çalışmada üretilen harçların 28 günlük basınç dayanımları 14,0 $\mathrm{MPa}$ ile 17,8 $\mathrm{MPa}$ arasında değişmiştir. Harçların basınç dayanımları kür yaşı ile birlikte artmış, 90 günlük harçların dayanımları 28 günlük dayanımlarına göre $\% 4$ ile $\% 27$ oranları arasında daha yüksek elde edilmiştir. Ayrıca, en yüksek basınç dayanımı değerlerine MK0 kodlu harçlarda ulaşılmıştır. Harçların basınç dayanımı değerlerine MK içeriğinin olumlu bir etkisi olmamıştır. \% Su emme oranı numunenin boşluk oranı ile orantılı olduğundan boşluk oranı arttıkça da Şekil 3'de görülen basınç dayanımında düşme olması beklenen bir durumdur [39]. Daha önceki çalışmalarda, aktive edilecek öncü malzemelerdeki (bu çalışmada SGA ve MK) toplam $\mathrm{SiO}_{2}$ içeriğinin $\mathrm{Al}_{2} \mathrm{O}_{3}$ kompozisyonuna oranı ile aktivatörlerdeki $\mathrm{Na}_{2} \mathrm{O}$ içeriğinin öncü malzemelerdeki $\mathrm{SiO}_{2}$ içeriğine oranının geopolimerlerin özelliklerini etkileyen en önemli parametreler olduğu belirtilmiştir. Bununla birlikte, yapılan birçok çalışmada da $\mathrm{SiO}_{2}$ içeriğinin $\mathrm{Al}_{2} \mathrm{O}_{3}$ kompozisyonuna oranının en önemli parametre olduğu rapor edilmiştir [40]. Bu nedenle çalışmamızda da $\mathrm{MK}$ içeriği ile birlikte laboratuvar koşullarında kür edilen SGA esaslı geopolimerlerdeki $\mathrm{Al}_{2} \mathrm{O}_{3}$ içeriğinin $\mathrm{SiO}_{2}$ içeriğine oranında kademeli olarak artış sağlanmış ve bu parametrenin de etkisi irdelenmiştir. Deney sonuçları SGA esaslı geopolimerlerdeki $\mathrm{SiO}_{2} / \mathrm{Al}_{2} \mathrm{O}_{3}$ oranı arttıkça basınç dayanımında artış, boşluk oranında da azalma tespit edilmiştir. Bu sonuçlar daha önce MK esaslı geopolimerler ile ilgili yapılan bir çalışma ile de uyumludur [41].

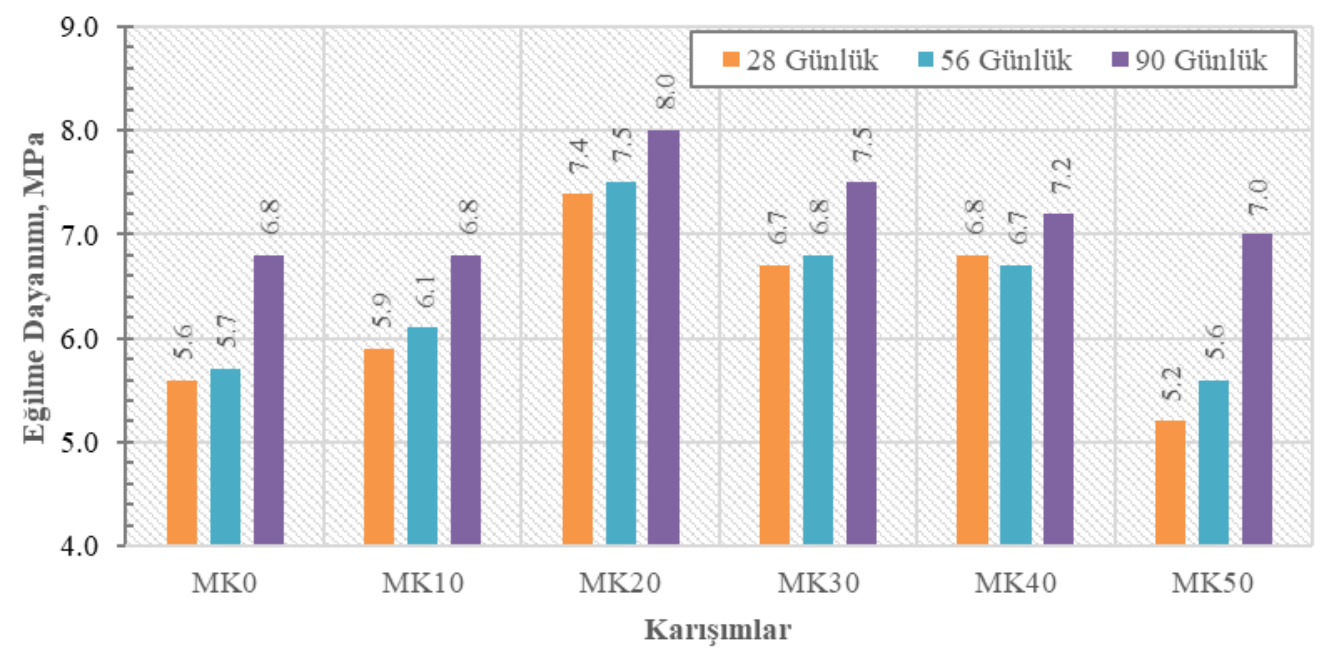

Şekil 1. Sertleşmiş harç numunelerinin eğilme dayanımı değişimi

Numunelerin artan kür süresi ve seramik sağlık gereci atığı yerine ilave edilen MK miktarı artışı ile eğilme dayanımları artarken, basınç dayanımları düşmektedir (Şekil 1-2). Numunelerde SGA yerine MK'nın kompozisyonlara dâhil olması ile Si/Al oranları değişecektir. Literatürde geopolimerik jel eğilimini arttırmada Si-O-Si bağlantısı, Al-O-Al veya Si-O-Al bağlantılarına göre daha etkin güce sahiptir [41-44]. Bu nedenle, SGA miktarı $\left(\mathrm{SiO}_{2}\right.$ miktarı yüksek) daha fazla olan numunelerin (MK0, MK10), $\mathrm{MK}$ içeriği $\left(\mathrm{Al}_{2} \mathrm{O}_{3}\right.$ miktarı yüksek) yüksek numunelere kıyasla basınç dayanımlarının Si-O-Si bağlantısına bağlı olarak yüksek değerlere ulaştığı düşünülmektedir. Bununla birlikte, öncü malzeme içeriğine bağlı olarak geopolimerik jel yapıları zincir şeklinde ve/veya birbirine çapraz bağlı şekilde meydana gelebilmektedir [46]. Alüminyum içeriği de alkali ile aktive edilmiş bağlayıcılardaki bu jel yapılarının oluşum şekillerini etkileyebilmektedir [47]. 
Çapraz bağlı jel yapılarının daha çok meydana geldiği geopolimerlerde boşluk oranının artması beklenirken, çapraz bağlar sayesinde de eğilme dayanımlarında artış olması da olağan bir sonuçtur. $\mathrm{Bu}$ çalışmada da, MK içeriği ile birbirine çapraz şekilde bağlı geopolimerik jel oluşumu azalan basınç dayanımına rağmen eğilme dayanımlarında meydana gelen artışı açıklamaktadır.

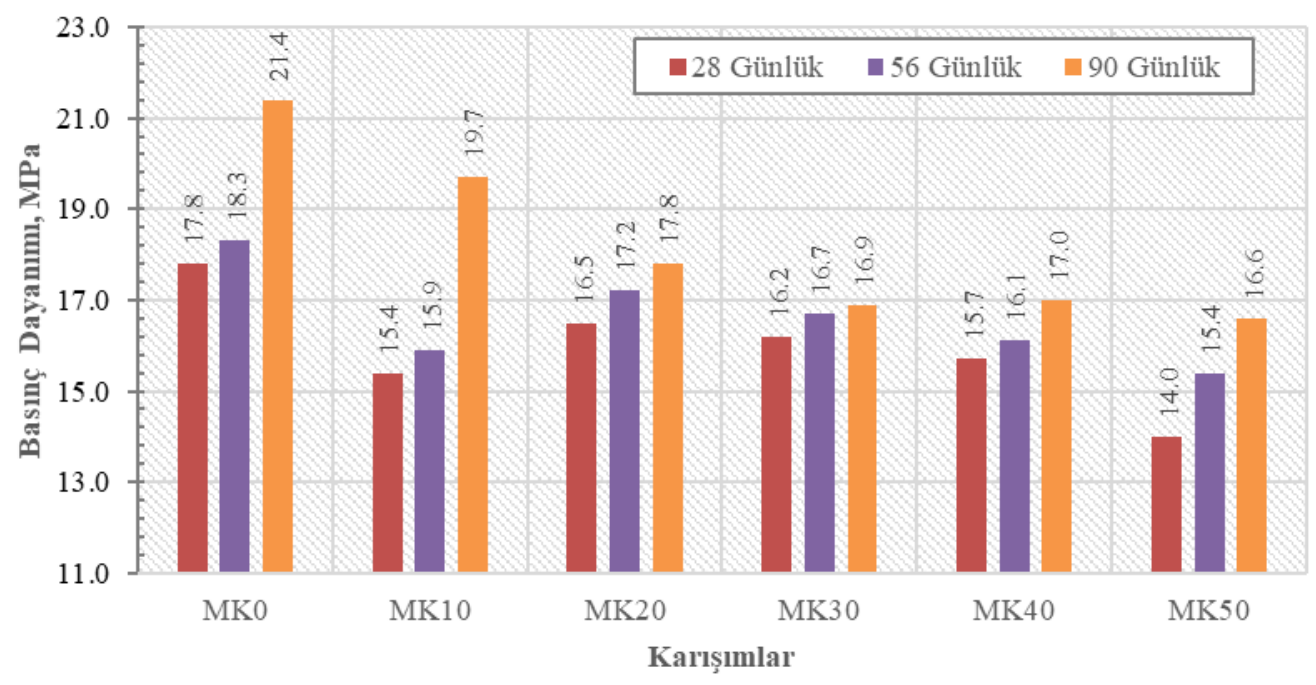

Şekil 2. Sertleşmiş harç numunelerinin basınç dayanımı değişimi

\section{Sonuç}

Yapılan bu deneysel çalışmada elde edilen bulgulara göre;

- SGA yerine metakaolen kullanılması birim ağırlık ve yayılma çapı değerlerini arttırmıştır.

- Su emme ve boşluk oranları değerleri, SGA yerine MK artışına bağlı olarak artmıştır.

- SGA esaslı geopolimer harçların eğilme dayanımları \%20 MK içeriğine kadar kademeli olarak artarken, basınç dayanımları MK içeriği ile birlikte azalmıștır. Bir başka deyişle, en yüksek basınç dayanımı değerlerine MK içermeyen harçlarda ulaşılırken, en yüksek eğilme dayanımı değerleri SGA yerine \%20 oranında MK içeren harçlarda elde edilmiştir.

- Basınç etkisinin daha etkili olduğu elemanlarda MK içermeyen harçların, eğilme etkisinin etkili olduğu elemanlarda ise SGA yerine \%20 oranında MK içeren harçların daha verimli olacağı düşünülmektedir.

- Bu çalışmada, literatürdeki birçok çalışmadan farklı olarak enerji verimliliği ve çevre sağlığ gözetilerek SGA ile ısıl kür uygulanmaksızın çimentosuz bağlayıcılar elde edilmiştir. Atıkların ekonomiye geri kazanımı açısından da SGA malzemesinin geopolimer üretiminde önemli bir potansiyele sahip olduğu söylenebilir.

- Farklı su içeriği ve aktivatör türü ile daha SGA esaslı geopolimerlerde yüksek mekanik özelliklerinin elde edilebilirliği ile bu geopolimerlerin dayanıklılık özelliklerinin araştırılması daha sonraki çalışmalar için önerilir.

Çalışma sonucunda, seramik sağlık gereci (SGA) atıklarının geopolimer harç üretimi açısından önemli bir potansiyele sahip olduğu anlaşılmıştır. Bu kapsamda değerlendirildiğinde atıkların ekonomiye geri kazanımı ve çevresel etkilerinin azaltılması mümkün olabilecektir. İleriki çalışmalar için, atık SGA kullanılarak farklı aktivatör ve farklı kür koşullarının dayanım ve dayanıklılık özelliklerine etkisinin incelenmesi önerilir.

\section{Teşekkür}

Çalışmada kullanılan seramik sağlık gereci atıklarının temininde destek olan Turkuaz Seramik Arge Merkezine (Kayseri) teşekkür ederiz. 


\section{Yazarların Katkıları}

ZBÖ malzeme temininde bulundu. SÇ ve İİA laboratuvarda numune üretimi ve testleri gerçekleştirdi. ZBÖ, SÇ ve İIA deney sonuçlarını değerlendirdi. ZBÖ literatür taraması yaptı ve makaleyi yazdı. SÇ ve İ́A makale yazımı sonrası düzenleme yaparak yayına hazırladı. Her üç yazar da makalenin son halini okuyarak onayladi.

\section{Çıkar Çatışması}

Yazarlar, çıkar çatışması olmadığını beyan eder.

\section{Kaynaklar}

[1]. Sun Q. ,Zhu H., Li H., Zhu H., Gao M., “Application of responce surface methodology in the optimization of fly ash geopolymer concrete", Romanian Journal of Materials, 2018, 48(1): 45-52.

[2]. Ibrahim A.K., Al-Kerttani O., Abbas S.R., “ Properties of geopolymer mortar subjected to high temperature”, Key Engineering Materials, 2020, 858: 193-198.

[3]. Singh B., Ishwarya G., Gupta M., Bhattacharyya S.K., "Geopolymer concrete: a review of some recent developments", Construction and Building Materials, 2015, 85: 78-90

[4]. Boum R. B. E., Kaze C.R., Nemaleu J.G.D., Djaoyang V.B., Rachel N.Y., Ninla P.L., Owono F.M., Kamseu E., "Thermal behaviour of metakaolin-bauxite blends geopolymer: microstructure and mechanical properties", SN Applied Sciences, 2020, 2: 1358.

[5]. Bingöl Ş., Bilim C., Atiş C.D., Durak U., İlkentapar S., Karahan O., "An investigation of resistance of sodium meta silicate activated slag mortar to acidic and basic mediums", Revista de la Construction, 2020, 19(1): 128-133.

[6]. Topçu, İ. B., Sofuoğlu, T. Pres Filtre Atığ1 ve Uçucu Kül ile Elde Edilen Geopolimer Harçların Farklı Koşullar Altında Birim Ağırlığı ve Basınç Dayanımının Değerlendirilmesi. El-Cezeri Fen ve Mühendislik Dergisi, 2020, 7(2): 806-823.

[7]. Rakhimova N.R., "A review of calcined clay sand ceramic wastes as sources for alkaliactivated materials", Geosystem Engineering, 2020, 23(5): 287-298)

[8]. Mwiti M. J.,Karanja T. J., Muthengia W. J., “" Thermal resistivity of chemically activated calcined clays based cements". RILEM Bookseries, 2018, 16: 327-333

[9]. Vickers L., Van Riessen A., Rickard W. D. A. "Precursor sand additives for geopolymer synthesis". In L. Vickers, A. vanRiessen, \& W. D. A. Rickard (Eds.), Fire resistant geopolymers - Role of fibres and fillers to enhance thermal properties, 2015, (pp. 17-37), Springer.

[10]. Zhang H. Y., Kodur V., Wu B., Cao L., Wang F., "Thermal behavior and mechanical properties of geopolymer mortar after exposure to elevated temperatures", Construction andBuildingMaterials, 2016, 109: 17-24.

[11]. Palomo A., Blanco-Varela M.T., Granizo M.L., Puertas F., Vazquez T., Grutzeck M.W., "Chemicalstability of cementitious materials based on metakaolin". Cement and Concrete Research, 1999, 29(7): 997-1004.

[12]. Lancellotti I.,Catauro M., Ponzoni C., Bollino F., Leonelli C., "Inorganic polymers from alkali activation of metakaolin: effect of setting and curing on structure", Journal of Solid State Chemistry, 2013, 200: 341-348.

[13]. Latella, B.A., Perera, D.S., Durce D., Mehrtens E.G., Davis J., "Mechanical properties of metakaolin-based geopolymers with molar ratios of $\mathrm{Si} / \mathrm{Al} \approx 2$ and $\mathrm{Na} / \mathrm{Al} \approx 1$ ", Journal of Materials Science, 2008, 43(8): 2693-2699. 
[14]. Yonar Y. "Geopolimer çimentolu ve polivinil alkol fiberli betonların yüksek sicaklık dayanıklılı̆̆ı”, Master thesis, Firat University Institute of Science, Elazı̆̆ 2014.

[15]. Sarkar M., Dana K., "Partial replacement of metakaolin with red ceramic waste in geopolymer", Ceramics International, 2021, 47(3): 3473-3483.

[16]. Reig L.,Soriano L., Borrachero M.V., Monzo J., Paya J., "Influence of the activator concentration and calciumhydroxide addition on the properties of alkali-activated porcelain stoneware", Construction and Building Materials, 2014, 68: 214-222.

[17]. Arsoy, Z., Çiftçi, H., Ersoy, B., Uygunoğlu, T., \& Arslan, B. Afyonkarahisar Bölgesi Mermer Parça Atıklarının Beton Agregası Olarak Değerlendirilebilirliğinin Araştırılması. El-Cezeri Fen ve Mühendislik Dergisi, 2019, 6(3): 503-516.

[18]. Kulkarni S. "Experimental study on red mud, flyash, GGBFS based geopolymer concrete", International Journal of Engineering Research Technology, 2018, 17(12): 107-111.

[19]. Mucsi G., Szabo R., Racz A., Kristaly F., Kumar S., "Combined utilization of red mud and mechanically activated fly ash in geopolymers", The Mining Geological- Petroleum Engineering Bulletin, 2019,34(1): 27-36.

[20]. Torres-Carrasco M., Puertas F., "Waste glass in the geopolymer preparation. Mechanical and microstructural characterisation". Journal of Cleaner Production, 2015, 90: 397-408.

[21]. Huseien G.F., Sam A.R.M., Shah K.W., Mirza J., Tahir M.M., "Evaluation of alkaliactivatedmortarscontaininghighvolumewasteceramicpowderandflyashreplacing GBFS". Construction and Building Materials, 2019, 210: 78-92.

[22]. Huseien G.F., Sam A.R.M., Shah K.W., Mirza J., "Effects of ceramic tile powder waste on properties of self-compacted alkali-activated concrete", Construction and Building Materials,2020, 236: 117574.

[23]. Rashad A. M., Essa G.M.F., "Effect of ceramic waste powder on alkali-activated slag pastes cured in hot weather after exposure to elevated temperature", Cement and Concrete Composites, 2020, 111: 103617.

[24]. Keppert M., Vejmelková E., Bezdicka P., Dolezelová M., Cáchová M., Scheinherrová L., Pokorny J., Vyšvar il M.,, Rovnaníková P., Cerny R., " Red-clay ceramic powders as geopolymer precursors: Consideration of amorphous portion and $\mathrm{CaO}$ content", Applied Clay Science, 2018, 161: 82-89.

[25]. Reig L., Tashima M. M., Soriano L., Borrachero M.V., Monzo J.. M., Paya J.J., “Alkaline activation of ceramic waste materials" Waste Biomass Valorization, 2013, 4: 729-736.

[26]. Reig L, Soriano L., Tashima M.M., Borachero M.V., Monzo J., Paya J., "Influence of calciumadditions on the compressive strength and microstructure of alkali-activated ceramic sanitary-ware". Journal of American Ceramic Society, 2018, 101: 3094-3104.

[27]. Atabey İ.İ., Bayer Ozturk Z., "Seramik Sağlık Gereci Atıklarının Geopolimer Harç Üretiminde Kullanılabilirliğinin Araştırılması", Uluslararası Mühendislik Araştırma ve Geliştirme Dergisi, 2021, 13(1): 212-219.

[28]. Bayer Ozturk Z., Can A., Yarımçam D., "Toprak Alkali Kaynağı Hammaddelerin Vitrifiye Surlarında Ergimeye Olan Etkisinin İncelenmesi”, El-Cezerî Fen ve Mühendislik Dergisi, 2021, 8(1): 195-201.

[29]. Kunduracı N., Tarhan B., Sarısakal C., "Seramik sağlık gereçleri üretiminde piroplastik deformasyon azaltılmasına bağlı olarak geliştirilen kompozisyonların üretim maliyeti açısından değerlendirilmesi”, Uluslararası Mühendislik Araştırma ve Geliştirme Dergisi,2019, 11(2): 474-480.

[30]. Acıkbas G., Gocmez H., "Polyester Matrisli Kompozit Özeliklerine Vitrifiye Seramik Sağlik Gereci Atık Miktarının Etkisi”, Akademik Platform Journal of Engineering Science, 2013, 5(3): 137-145.

[31]. Medina C., Frias M., Sanchez de Rojas M.I., "Microstructure and properties of recycled concretes using ceramic sanitaryware industry waste as coarse aggregate", Construction and Building Materials, 2012, 31: 112-118. 
[32]. Deb P.S.,Nath P., Sarker P.K., "The effects of ground granulated blast-furnace slag blending with fly ash and activator content on the workability and strength properties of geopolymer conctrete cured at ambient temperature", Materials Design, 2014, 62: 32-39.

[33]. Yurt U., Emiroğlu M., “Zeolit İkameli Geopolimer Betonlarda Kür Şartlarının Etkileri”, Akademik Platform Journal Engineering Science, 2020,8(2): 396-402.

[34]. Kaya M., Uysal M., Yılmaz K., "Jeopolimer harçlarda dayanım, kür sıcaklığı ve boşluk oranı ilişkisinin varyans analizi ile incelenmesi”, Sakarya Üniversitesi Fen Bilimleri Enstitüsü Dergisi, 2018, 22(2): 248-256.

[35]. TS EN 1097-6, Agregaların mekanik ve fiziksel özellikleri için deneyler - Bölüm 6: Tane yoğunluğunun ve su emme oranının tayini, Türk Standartları Enstitüsü, Ankara, 2013.

[36]. TS EN 1008, Beton-Karma suyu-Numune alma, deneyler ve beton endüstrisindeki işlemlerden geri kazanılan su dahil, suyun, beton karma suyu olarak uygunluğunun tayini kuralları, Türk Standartları Enstitüsü, Ankara, 2003.

[37]. TS EN 1015-3/A1, Kagir harc1- Deney metotlar1- Bölüm 3: Taze harç kıvamının tayini (yayılma tablası ile), Türk Standartları Enstitüsü, Ankara, 2006.

[38]. TS EN 1015-11/A1, Kâgir Harc1-Deney Metotlar1-Bölüm 11: Sertleşmiş Harcın Basınç ve Eğilme Dayanımının Tayini, Türk Standartları Enstitüsü, Ankara, 2013.

[39]. Erdoğan, T. Y. Beton (4. bs.) [Concrete (4th ed.)]. METU Publishing, 2013, Ankara, 757p

[40]. Chen, X.,Niu, Z., Wang, J., Zhu, G. R.,Zhou, M., "Effect of sodium polyacrylate on mechanical properties and microstructure of metakaolin-based geopolymer with different $\mathrm{SiO}_{2} / \mathrm{Al}_{2} \mathrm{O}_{3}$ ratio."Ceramics International, 2018, 44(15): 18173-18180.

[41]. Ross A. Fletcher, Kenneth J.D. MacKenzie, Catherine L. Nicholson, et al.,"The composition range of aluminosilicate geopolymers,", Journal of the European Ceramic Society 2005, 25 $1471-1477$

[42]. De Jong B., Brown Jr G.E., "Polymerization of silicate and aluminate tetrahedra in glasses, melts, and aqueous solutions- $-\mathrm{I}$. Electronic structure of $\mathrm{H}_{6} \mathrm{Si}_{2} \mathrm{O}_{7}, \mathrm{H}_{6} \mathrm{AlSiO}_{71}$, and $\mathrm{H}_{6} \mathrm{Al}_{2} \mathrm{O}_{72-}$, Geochim. Cosmochim. Acta, 1980, 44 (3): 491-511.

[43]. Duxson P.,Drovis J.L., Lukey G.C., Mallicoat S.W., Kriwen W.M., Van Deventer S.J.V, "Understanding the relationship between geopolymer composition, microstructure and mechanical properties", Colloids and Surfaces A: Physicochemical and Engineering Aspects 2005, 269 (1-3): 47-58.

[44]. Si R.,Guo S., Dai Q., Wang J. “Atomic-structure, microstructure and mechanical properties of glass powder modified metakaolin-based geopolymer", Construction and Building Materials, 2020, 254: 119303.

[45]. Çelikten, S.,\& Atabey, İ. İ. Su içeriği ve ısıl kür süresinin atık bazalt tozu esaslı geopolimer harçların fiziksel ve mekanik özelliklerine etkisi. Niğde Ömer Halisdemir Üniversitesi Mühendislik Bilimleri Dergisi, 2021, 10(1): 328-332.

[46]. Marjanovic' ,N., Komljenovic', M., Baščarevic' Z., Nikolic' V., Petrovic' R., "Physicalmechanical and microstructural properties of alkali-activated fly ash-blast furnace slag blends", Ceramics International, 2015, 41 (1): 1421-1435

[47]. Alkali Activated Materials,State-of-the-Art Report RILEM TC 224-AAM, In: J.L.Provis, J.S.J. Van Deventer (Eds.), Springer, Dordrecht, Heidelberg, New York, London, 2014. 